\title{
Progress in Organ Donation and Transplantation: A Critical Review of Literature
}

\author{
Peter Masibinyane Dimo \\ ${ }^{1}$ Department of Social Work, KwaDlangezwa Campus, South Africa \\ Correspondence: Peter Masibinyane Dimo, Department of Social Work, KwaDlangezwa Campus, South Africa. \\ Tel: 27-35-902-6664. E-mail: DimoP@unizulu.ac.za; charismadimo@gmail.com
}

Received: November 9, 2019 Accepted: December 3, 2019 Online Published: August 28, 2020

doi:10.5539/gjhs.v12n10p133 URL: https://doi.org/10.5539/gjhs.v12n10p133

\begin{abstract}
The majority of countries are battling with a high incidence of organ failure such as the kidneys, heart, lungs, pancreas, and liver. The only solution that can remedy the plight of patients facing the strong likelihood of death as a result of malfunctioning body organs is organ donation and transplantation. The intention of this literature study is to assess progress in organ donation and transplantation. This study has benefitted immeasurably from previous scientific investigations. Four hundred and thirty-one published papers were selected from different accredited journals. The study found that many of the countries that have implemented the opt-in system are struggling to close the gap between the high demand for and the actual availability of life-saving organs due to low rates of registered and committed organ donors. The majority of patients that are contending with end-stage diseases are added to the organ donation waiting lists, but have little hope of receiving life-prolonging organs. Among the factors that deter people from contributing to organ donation and transplantation are a lack of knowledge, the failure to obtain consent from family members or next-of-kin, social attitudes, socio-cultural aspects, and myths. This study recommends urgent measures that could be taken to increase organ transplants in public and private hospitals due to the chronic shortage of organs for transplantation and by introducing the opt-out system of organ donation.
\end{abstract}

Keywords: progress, organ, donation

\section{Introduction and Background of the Study}

Good health is a prerequisite for the normal functioning of all people at all ages. With good health, people are able to participate meaningfully in life activities and in their country's welfare. It is the responsibility of all countries, through its policies, to ensure that its citizens are in good physical, psychological, social, and emotional health. It is against this background that the United Nations adopted 17 sustainable developmental goals, the purpose of which was to ensure that people are healthy and also live on a healthy planet. However, the realisation of this important goal it is not without limitations. The majority of countries in both developing and developed countries are battling with the high incidence of end-stage diseases. According to Rabinowic and Jotkowitz (2018), the increasing prevalence of end-stage organ disease is creating an acute shortage of transplantable organs. It is indisputable that the hope of patients suffering from end-stage diseases and facing the reality of death is organ donation and transplantation. Tamuli, Sarmah, and Saikia (2017) define organ donation as a medical procedure whereby a person allows their vital body organs to be removed, legally and by consent, while they are still alive or after death with the consent of the family or the next-of-kin. While organ transplantation is seen as a means of grafting human body organs from a living person or deceased organ donor into a living person for therapeutic purposes (Yadav, Jakhar, Giri, Jain, Dahiya \& Dhattarwal, 2018), body organs that can be donated are the kidneys, heart, liver, pancreas, intestines, lungs, bones, bone marrow, skin, and corneas. Organ donation is a definite therapy for end-stage diseases. The purpose of this study is to examine the progress in organ donation and transplantation both at a national and international level. However, South Africa will receive dominant attention. Furthermore, this study explores and assesses factors that hinder organ donation and transplantation in various countries and investigates the remedial steps that can be taken to assist these countries despite the low supply of organs.

\subsection{Significance of the Study}

In many countries, organ donation is not a new subject, however it is a subject that is under-researched in countries like South Africa. Therefore, this study will stimulate research in this field, particularly where there is a dearth of 
scientific investigation. Furthermore, it will stimulate constructive debate and discourse that will culminate in the identification of long-lasting solutions. It is also aimed at challenging the existing legal systems that are in place in countries that are struggling to close the widening gap between the demand and the actual supply of organs.

\subsection{Theoretical Frameworks}

This study adopted multiple lenses through which to understand and analyse organ donation and transplantation from diverse perspectives. The Theory of Planed Behaviour, Eco-System Theory, Theory of Social Constructivism, and the Theory of Social Marketing were used as the theoretical frameworks for this literature study. Social scientists believe that all behaviour is learnt and planned. The Theory of Planned Behaviour is helpful in understanding the intentions and the, decision-making of people. Kassim, Arokiasamy, and Ping (2019) state that the behaviour of human beings is too complex to be understood. Nevertheless, the behaviour is interpretable with significant focus on biological and environmental factors on behaviour. According to this theory, an individual's social attitudes and personality traits play a pivotal role in explaining behaviour. In addition to this assertion, Choi and Lee (2018) state that a change of behaviour requires distinct predictive mechanisms. It is essential to identify and understand social factors that can influence people to sign an organ donor card because multiple factors influence organ donation. The researcher argues that the environment within which organ donation and transplantation are promoted play a crucial role. According to the Eco-System Theory, people have a relationship with their environment and to a large extent their behaviour is influenced by the environment in which they live. In addition, this perspective is based on the philosophy that human beings are part of a bigger system, interrelated, and interdependent. They have the ability to influence one another. It is vital to view and understand people's organ donation behaviour within their different contexts. Information about organ donation and transplantation come to people through many channels, thus it is imperative to explore how people learn, and therefore the Theory of Social Constructivism is appropriate for this study. According to this theory, knowledge is socially constructed through interaction. According to Hang, Bulte, and Pilot (2017), knowledge is social, experience-based, and socially constructed. This theory was used in conjunction with the Theory of Social Marketing. The marketing and the promotion of organ donation play a pivotal role. The Theory of Social Marketing was employed to investigate how organ donation and transplantation are promoted.

\section{Methods}

A literature review was adopted as the methodology for this study. Publications that explicitly deal with organ donation and transplantation were targeted. A total of 431 peer-reviewed publications were retrieved from different databases such as Ebscohost, Sabinet, and Google Scholar. Different key words such as organ donation, transplantation, donation rates, knowledge about organ donation, organ donation behaviour, attitudes in organ donation, and challenges in organ donation were used. This literature study targeted, peer-reviewed studies documents, and reports that were published between 2010-2019 only.

\subsection{Problem Statement}

Many developing and developed countries are battling with the high incidence of end-stage diseases such as heart attacks, kidney failure, hypertension, diabetes, obesity, and liver problems, which invite organ donation and transplantation. Organ donation and transplantation are significant life-saving strategies in the medical arena and they have improved many patients' quality of life, especially those who were facing the reality of death. Many organ donation researchers describe organ donation and transplantation as fundamental therapy for the majority of people who experience chronic organ failure. Donated human body organs and tissues are transplanted into the body of a living person in order to replace their malfunctioning organs. The purpose of organ donation and transplantation is to save lives and improve the quality of lives (Bhatia \& Tibballs, 2017). However, the majority of countries in the world are challenged by the scarcity of transplantable organs. According to Srivastava and Mani (2018), there is a disparity between the demand and the supply of human body organs, both from the living and deceased organ donors. Williams and Muir (2018), concur with these findings and they emphasise that there is an acute shortage of available transplantable organs while the number of patients expecting transplants increases greatly. The lack of transplantable organs has detrimental consequences because the majority of patients die before they receive life-saving organs (Descourouez, Richards, Sam, \& Crowther, 2014). This assertion is supported by Sindhu, Ramakrishnan, Khera, and Singh (2017), who also state that approximately 500,000 people die annually as a result of the non-availability of vital body organs. It is a financial burden to take care of patients that are suffering from end-stage diseases. It brings physical, psychological, and emotional distress to the patients' family members and the next-of-kin. The Organ Donor Foundation (2018) reports that South Africa has approximately 4,300 patients suffering from end-stage diseases, and only $0.2 \%$ of prospective organ donors who indicated their willingness to donate their organs after death by signing an organ donor card. Spiers and Smith (2016) state that the 
United Kingdom had approximately 6,000 patients who were waiting for a kidney donation in 2013. In addition to these shocking statistics, Li et al. (2017) report that Canada had approximately 4,400 patients on the waiting list in 2013, and almost 246 died without receiving an organ.

\subsection{Data Analysis}

The research literature defines data analysis as a scientific process of bringing order and structure to collected data. In this study data was collected through a literature review or document analysis. Although the researcher did not interact or interview participants, data in this study was analysed via thematic content analysis. The discussions and the debates in this study are presented and discussed according to the major themes that emerged from the different studies that were consulted.

\section{Findings}

This study's findings reveal that the majority of countries are still using the opt-in system of organ donation, and despite this, countries that use the opt-in system are still finding it difficult to increase the volume of organ donors. The study also found that there are discrepancies between the demand and the actual supply of human body organs. In many countries, organ donation is characterised by low rates of organ donation, as the majority of people are not legally registered as organ donors. Most families are reluctant to give consent to allow the harvest of the deceased's vital body organs. Lack of insight about organ donation and transplantation is still considered to be a formidable barrier in organ donation and transplantation.

\section{Discussions of Findings}

The rates of organ donation and transplantation are determined by different countries' legal policies in terms of organ donation. Organ donation statutes are categorised into opt-in or opt-out systems. This study's findings indicate that the majority of countries use the opt-in system of organ donation, although some countries explicitly use the opt-out organ donation system. South Africa, which is struggling to close the widening gap between the demand and the actual supply of vital body organs uses the opt-in organ donation system. Amongst the countries still using this kind of a system are South Africa, United States, Slovenia, England, New Zealand, and Canada (Etheredge, Penn, \& Watermeyer, 2018; Kamin, Berzelak, \& Ule, 2017; Zambrano, 2017). Zuniga-Fajuri (2015) describe the opt-in system as a system that requires a prospective organ donor to express consent to become an organ donor, while the opt-out system presumes consent unless an individual expresses their refusal to participate in organ donation. The opt-in system is human rights-based and people are not under compulsion to participate in organ donation, and under this system, organ donation is seen as an act love. Unfortunately, the majority of countries that use this system have low donation rates and ever increasing organ waiting lists. Only $0.2 \%$ of prospective South African organ donors signed the organ donor card. In addition to this alarming statistics, around 4,300 patients are suffering from end-stage diseases in South Africa (Organ Donor Foundation, 2018). Henderson and Gross (2017) state that the United States of America has more than 120,000 patients waiting for a life-saving organ. In 2013, Canada had 4,400 patients on the waiting list, and 246 patients died. Furthermore, Capone, Alurkar, Kigozi, and Vyas (2018), report that approximately 10,000 patients are on the waiting list in United Kingdoms. The acute shortage of transplantable organs has disastrous consequences. It is estimated that more than 7,000 deaths occur annually due to a lack of available organs.

The majority of studies in different countries indicate that the opt-in system is incapacitated by the family members or next-of-kin's hesitancy to grant consent. In the case of deceased organ donors, the family plays a crucial role in organ donation and transplantation, despite the prospective organ donor's willingness and commitment. Furthermore, one can safely conclude that a signed donor card does not give transplant units the authority to harvest organs. In the social work discipline, a family is seen as a system where family members are interrelated. This study has adopted the Eco-System Theory as one of its theoretical frameworks. According to Mbedzi, Qalinge, Schultz, Sekudu, and Sesoko (2015), people should understand their contexts, the people they interact with, and the impacts of those interactions.

\subsection{Informed Consent in Organ Donation}

Informed consent is the cornerstone of medical social work practice and medicine. In addition to this, medicine and social work practice are human-rights-based professions. Patients, clients, or service-users are given the opportunity to make their own decisions. According to Mbedzi et al. (2015) family members are considered to possess the capacity to determine what they want for their deceased family member, and social workers, doctors, and nurses are ethically bound to respect the choices of their clients or patients. Schatz et al. (2017) describe informed consent as a process that should be carried before healthcare interventions are conducted. The intention of informed consent is to inform a patient about the type and the severity of their disease, provide a medical 
diagnosis, and describe medical treatment and their benefits and risks, and as a result, a patient is then in a strong position to grant autonomous and voluntary consent. Toews and Caulfield (2016) declare that the practice of respecting a family's objections to donation over the deceased's validly executed consent affects access to life-saving organs. In 2005, Spital declared that the refusal to allow organ recovery is one of the greatest reasons for the loss of available organs. It is estimated that almost $50 \%$ of families' decline to grant consent for organ harvest and transplant. Failure to obtain consent for the retrieval of a deceased organ donors' organs is caused by various factors, such the lack of communication about organ donation. Death is a sensitive subject, and the majority of people are not comfortable discussing it. According to Anthony, Toews, Caulfield, and Wright (2017), the majority of people oppose the wishes of the deceased organ donors wishes due lack of information or lack of adequate communication. In addition to this view, Hyde and White (2013) believe that discussing organ donation increases the likelihood that family members will consent to the organ donation of their loved ones. Although communication is crucial in organ donation, Hyde and White discovered that almost $40 \%$ of Australians are unaware of the intentions of their family members.

\subsection{Lack of Awareness About Organ Donation}

The prerequisites of organ transplantation and organ donation is important information to disseminate. Nevertheless, the majority of studies that have been consulted cite a lack of awareness or information about organ donation as a major barrier to organ donation and transplantation. Although organ donation is not a new therapy in either developing or developed countries, Krupic, Sayed-Noor, and Fatahi (2017) indicate that organ donation and transplantation are the most successful medical advances over the past 60 years. A lack of awareness and scant insight into the subject do have an impact on organ donation (Srivastava \& Mani, 2018). In order to eradicate the chronic shortage of vital body organs, it is important to eliminate a lack of awareness (Karabıçak, Turk, Oruc, Ozdogan, Cinkaya, Karaca, \& Zorlu, 2018). While many writers blame a lack of information about organ donation on successful recruitment of donors, the researcher believes that it is crucial to assess how people learn about organ donation and transplantation, where they get their information, and the frequency of messages disseminated about organ donation and transplantation. Furthermore, this study does not dispute the fact that information is a powerful weapon that could be used to modify organ donation behaviour in the public, their attitudes, and their perceptions. In addition to these aspects, the manner in which the marketing of organ donation and transplantation is approached is of great significance. This study is based on the Theory of Social Marketing, which, according to Schwartz (1971), as cited in Correio, Pereira, Resende, and Rezende (2017), social marketing is defined as a way of planning a programme in a large organisation with the aim of influencing voluntary behaviour in a determined segment of the population with a social purpose rather than a financial objective. The focus of social marketing is on the social aspects. Mani, Danasekaran, and Annadurai (2016) conclude this debate by stating that ample information about organ donation is associated with significantly positive attitudes towards organ donation and transplantation.

\subsection{Social and Cultural Factors}

According to Kamin, Berzelak, and Ule (2017), organ donation and transplantation comprise social, cultural, and psychological aspects. It is extremely crucial to design marketing strategies that are relevant to diverse contexts and that address critical aspects that prevent people from participating in organ donation. This study maintains that organ donation marketing strategies should target context-specific social aspects. The study also found the majority of people in different countries have positive attitudes about organ donation and the transplantation of organs. According to Vlaisavljevic, Jankovic, and Soldatovic (2017), attitudes regarding organ donation can either be positive or negative. They define attitudes as "enduring mental, neural, readiness that is acquired on the basis of experience which directly or dynamically stimuluses the reaction of an individual to objects and situations with which they are in touch". Positive attitudes are vital in organ donation and they are also influenced by several aspects, such information about organ donation, religious beliefs, and the potential donor's socio-economic status. Etheredge, Turner, and Kahn (2013) established that almost 70\% of the population are willing to have their body organs donated subsequent to their deaths. This assertion is supported by Stephenson et al. (2008), who report that people have overwhelming positive attitudes towards organ donation. Nevertheless, despite these encouraging attitudes and support for organ donation and transplantation, there is no positive correlation between the number of people who are signing organ donor cards and the supply of organs. Transplants programmes are still experiencing a severe dearth of life-saving organs due to a lack of committed organ donors.

Cultural and emotional factors are among the obstacles that hinder the donation of organs and the medical practice of transplantation of body organs. Culture is an important aspect of human beings, irrespective of race. People are empowered by their countries' constitutions to freely practice their cultures. Chapter Two of the Constitution of 
Republic of South Africa confers on South Africans the right to practice their religion and culture without fear. All major South African policies and legislation are based on the Constitution as the supreme law of country. In addition to this fundamental truth, the legal system of organ donation is also based on human rights, particularly the opt-in system that is used in many countries. Many researchers view culture as an almost impenetrable barrier that stands between organ donation and the general public, since very often it prescribes how people should behave. Culture helps people to identify who they are, including their past, their present, and their future. It is transmitted from one generation to the next generation through socialisation. The researcher presents and maintains that culture has a crucial role to play in organ donation and transplantation, as it shapes the attitudes and the perceptions regarding organ donation. Thus, it is imperative for medical practitioners, professional nurses, and medical social workers to approach organ donation with cultural sensitivity and wisdom and furthermore, to be able to quickly identify sensitive cultural boundaries in different communities. According to Chironda and Bhengu (2016), the donation of organs is hampered by cultural traditions, social norms, and ethical principles. According to African Culture, a person is reunited with their ancestors after death, and it is believed that ancestors cannot recognise a person with missing body organs. Chironda and Bhengu (2016) state that in African culture, particularly in South African cultures, a dead person with an incomplete body prior to burial or cremation is associated with misfortune.

\subsection{Religious Factors}

Human beings are social, psychological, spiritual, physical, and religious beings and additionally, from a biblical perspective, they are spirit, soul, and the body. All these aspects are extremely important if human beings are to be understood. In an attempt to discover the barriers that prevent people from participating in organ donation and transplantation, the majority of studies point to a lack of information, to the emotional and spiritual aspects, cultural values, socioeconomic aspects, and religious factors, and these factors are considered to influence the organ donation behaviours of South Africans (Zargham, Dorestan, Bahadoram, \& Bahadoram, 2018; Krupic et al., 2018). People have different definitions of religion that are determined by the contexts in which they find themselves and their socialisation. For the purpose of this paper, the author uses Larsen and Rinkel's definition of religion (2016), who conceptualised religion as a set of institutionalised behaviours, beliefs, and rituals shared by communities with similar beliefs. This definition reveals that religion takes different forms of learning, whether structured or unstructured. From this definition one can conclude that religion is a question of transmitting peoples' thoughts, ideas, actions, and discourses from one generation to another. It is imperative to understand the power of religion in organ donation and transplantation, because through religion attitudes and behaviours are regulated. Religion clearly prescribes what is right and wrong. The majority of studies established that religion is one of the major barriers that has created a wall that prevents people from participating in organ donation. It is not the purpose of this paper to discover the positions of different religions regarding organ donation and transplantation, but the majority of religions do encourage sacrificial giving that is motivated by love. According to Tarus (2015), from a religious perspective, irrespective of the denomination, organ donation and transplantation is not considered a call to altruistic behaviour, charity actions, or unconditional love, since these acts of giving are supposed to be anonymous.

\section{Conclusions}

The sole purpose of this paper was to measure the progress in organ donation and transplantation both globally and nationally, although more attention was given to South Africa because of its current status quo in terms organ donation. The majority of authors lament the chronic shortage of organs and organ donors. Many countries still use the opt-in system of organ donation, but it is cited as being ineffective in reducing or closing the widening gap between organ supply and demand. This significant imbalance has calamitous repercussions as more patients are added to the waiting list on daily basis, without any assurance that they will receive life-saving organs in time to live. The harsh reality is that the majority of these patients die while waiting for a suitable donor. A throng of multifaceted factors, such as lack of awareness about organ donation and transplantation, socio-cultural factors such as culture, religion, and attitudes, and a shortage of organ donors in many countries are amongst the factors that are responsible for the draught of organs. Informed consent is crucial in organ donation but many studies report that the majority of family members or next-of-kin refuse to grant permission for the harvest of organs from their family members, and such refusal to grant permission is intertwined with lack of information about organ donation.

\subsection{Recommendations}

The task of seeking meaningful and enduring solutions to the shortage of organs and donors is urgent and it is the obligation of all stakeholders in governments to press ahead with urgency in an effort to do so. The lack of information about organ donation and transplantation seems to be the engine driving the problem that affects many 
countries. It is in the light of this finding, that this paper recommends that public education regarding organ donation and transplantation be prioritised and strengthened. Different countries' education authorities need to consider introducing organ donation into school curricula because children are effective agents in spreading information. Additionally, the voice of faith-based organisations regarding organ donation and transplantation is not loud enough. Involving churches in organ donation information dissemination is crucial because religion is one of the barriers that prevents people from participating in organ donation. Human beings are complex in nature, and the factors that contribute towards their complexity, such as psycho-social, religious, and cultural factors and their attitudes should be investigated carefully and organ donation programmes that are cognisant of such factors should be designed. Such initiatives will stimulate further research into organ donation and transplantation that has the capacity to pave the way for effective intervention strategies. The study recommends that countries experiencing a lack of organs available for donation should objectively assess their policies that regulate the donation of tissues and body organs, in order to see whether or not these policies are in fact in the best interest of citizens. The introduction of the opt-out model of organ donation seems to be an alternative that is largely ignored by many countries and yet it has the ability to change organ donation efficacy.

\section{Competing Interests Statement}

The authors declare that there are no competing or potential conflicts of interest.

\section{References}

Anthony, S. J., Toews, M., Caulfield, T., \& Wright, L. (2017). Family veto in organ donation in Canada: framing within English-language newspaper articles. Canadian Medical Association Journal, 5(4). 768-772. https://doi.org/10.9778/cmajo.20170051

Bhatia, N., \& Tibballs, J. (2017). The development of property rights over cadaveric tissues and organs: legal obstructions to the procurement of organs in an "opt-out" system of organ donation in Australia and New Zealand. New Zealand Universities Law Review, 27: 947-974.

Carone, L., Alurkar, S., Kigozi, P., \& Vyas, H. (2018). Organ and tissue donation in a regional paediatric intensive care unit: evaluation of practice. European Journal of Pediatrics, 177, 709-714. https://doi.org/10.1007/s00431-017-3084-8

Chironda, G., \& Bhengu, B. (2016). Ethical, legal and cultural implications in the management of chronic kidney disease (CKD) patients: a critical review of literature. Transactions of the Royal Society of South Africa, 71(2), 137-143. https://doi.org/10.1080/0035919X.2016.1146928

Choi, Y. Y. J. N., \& Lee, K. (2018). Theory of Planned Behaviour and different forms of organizational change behaviour. Social Behaviour and Personality, 46(10), 1657-1672. https://doi.org/10.2224/sbp.6832

Correio, C. V. S., Pereira, J, R., Resende, L. C. B., \& Rezende, L. B. O. (2017). Donate to save: an analysis of the intention to donate organs under the perspective of social marketing. Revista Gestao \& Tecnologia, Pedro Leopoldo, 17(1), 10-35. https://doi.org/10.20397/2177-6652/2017.v17i1.1113

Descourouez, J., Richards, K. R., Sam, T., \& Crowther, B. (2014). Expanding the role of pharmacists and pharmacy students in the promotion of organ donation awareness. Progress in Transplantation, 24(2), 189-191. https://doi.org/10.7182/pit2014293

Etheredge, H., Penn, C., \& Watermeyer, J. (2017). Opt-in or opt-out to increase organ donation in South Africa? Appraising proposed strategies using an empirical ethics analysis. Developing World Health Bioethics, 18, 119-125. https://doi.org/10.1111/dewb.12154

Etheredge, H. R., Turner, R. E., \& Kahn, D. (2013). Public attitudes to organ donation among a sample of urban-dwelling South African adults: a 2012 study. Clinical Transplantation, 27, 684-692. https://doi.org/10.1111/ctr.12200

Hang, N. V. T., Bulte, A. M. W., \& Pilot, A. (2017). Interaction of Vietnamese teachers with a social constructivism-based primary science curriculum in a framework appropriate for a Confucian heritage culture. Asia Pacific Science Education, 3(2), 2-33. https://doi.org/10.1186/s41029-017-0013-0

Henderson, M. L., \& Gross, J. A. (2017). Living Organ Donation and Informed Consent in the United States: Strategies to Improve the Process. Journal of Law, Medicine and Ethics, 45, 66-76. https://doi.org/10.1177/1073110517703101

Hyde, M. K., \& White, K. M. (2013). A test of three interventions to promote people's communication of their consent for organ donation. Journal of Psychology and Health, 28(4), 399-417. 
https://doi.org/10.1080/08870446.2012.731060

Kamin, T., Berzelak, J., \& Ule, M. (2017). Mind the gap: social aspects of willingness for post-mortem organ donation in Slovenia. Teorija in praksa, 54(4), 732-746.

Karabıçak, M., Turk, H., Oruc, I., Ozdogan, S., Cinkaya, A., Karaca, C., \& Zorlu, F. (2018). Knowledge attitude and behaviour in the domain of organ transplantation among healthcare professionals working in a tertiary care hospital and patients admitted to the urology clinic. Journal of Urological Surgery, (1), 13-17. https://doi.org/10.4274/jus. 1058

Kassim, K. N. A., Arokiasamy, L., \& Ping, C. H. (2019). Intention to Purchase Safer Car in Indonesia: An Application of Theory of Planned Behaviour. Global Business and Management Research: An International Journal, 11 (1), 455-460.

Krupic, F., Sayed-Noor, A. S., \& Fatahi, N. (2017). The impact of knowledge and religion on organ donation as seen by immigrants in Sweden. Scandinavian Journal of Caring Sciences, (31), 687-694. https://doi.org/10.1111/scs.12379

Larsen, K. M., \& Rinkel, M. (2016). What does religion and spirituality mean to a racially diverse group of social work practitioners? Journal of Religion \& Spirituality in Social Work: Social Thought, 35(3), 200-221. https://doi.org/10.1080/15426432.2016.1185990

Li, A. H., Garg, A. X., Prakash, V., Grimshaw, J. M., Taljaard, M., Mitchell, J., ... \& Presseau, J. (2017). Promoting deceased organ and tissue donation registration in family physician waiting rooms (RegisterNow-1 trial), study protocol for a pragmatic, stepped-wedge, cluster randomized controlled registry. Biomedical Central, 1-13. https://doi.org/10.1186/s13063-017-2333-5

Mani, G., Danasekaran, R., \& Annadurai, K. (2016). Perceptions and practices related to organ donation among a rural population of Kancheepuram district, Tamil Nadu, India. Journal of Comprehensive Health, 4(1), 72-84.

Mbedzi, P., Qalinge, L., Schutz, P, Sekudu, J., \& Sesoko, M. (2015). Introduction to social work in the South African context. South Africa: Oxford University Press.

Organ Donor Foundation report. (2018).

Rabinowich, A., \& Jotkowitz, A. (2018). Altruism and religion: a new paradigm for organ donation. Journal Religious Health, (57), 360-365. https://doi.org/10.1007/s10943-017-0488-8

Sadic, F., Custovic, S., Jasarevic, M., Fazlic, M., \& Samuelsson, K. (2018). The effect of changing one's country of residence on the decision to become an organ donor: the experience of religious immigrant women living in Sweden. Medicinski, 15(2), 192-198.

Schatz, T., Haberstroh, J., Bindel, K., Oswald, F., Pantel, J., Paulitsch, F., Konopik, N., \& Knopf, M. (2017). Improving comprehension in written medical informed consent procedures. Full-length Research Report, 30(3), 97-108. https://doi.org/10.1024/1662-9647/a000169

Sindhu, A., Ramakrishnan, T. S., Khera, A., \& Singh, G. A. (2017). study to assess the knowledge of medical students regarding organ donation in a selected college of Western Maharashtra. Med J DY PatilUniv, 10, 349-53. https://doi.org/10.4103/MJDRDYPU.MJDRDYPU_258_16

Spiers, J., \& Smith, J. A. (2016). Waiting for a kidney from a deceased donor: an interpretative phenomenological analysis. Psychology, Health and Medicine, 21(7), 836-844. https://doi.org/10.1080/13548506.2015.1112415

Spital, A. (2005). Should people who commit themselves to organ donation be granted preferred status to receive organ transplants? Clinical Transplants, 19, 269-272. https://doi.org/10.1111/j.1399-0012.2005.00336.x

Srivastava, A., \& Mani, A. (2018). Deceased organ donation and transplantation in India: Promises and challenges. Neurology Society of India, 66(2), 316-322. https://doi.org/10.4103/0028-3886.227259

Stephenson, M. T., Morgan, S. E., Roberts-Perez, S. D., Harrison, T., Afifi, W., \& Long, S. D. (2008). The role of religiosity, religious norms, subjective norms, and bodily integrity in signing an organ donor card. Health Communication, 23, 436-447. https://doi.org/10.1080/10410230802342119

Tamuli, R. P., Sarmah, S., \& Saikia, B. (2017). Organ donation - "attitude and awareness among undergraduates and postgraduates of North-East India". Journal of Medicine and Primary Care, 8(1), 131-136.

Tarus, L. (2015). A sociological perspective on the role of the church in organ transplantation. Social Research Reports, 27, 133-143. 
Toews, M., \& Caulfield, T. (2016). Evaluating the "family veto" of consent for organ donation. Canadian Medical Association Journal, 6, 17-18. https://doi.org/10.1503/cmaj.160752

Tumin, M., Noh, A., Satar, N. M., Tafran, K., Abdullah, N., Adnan, W. A. H. M., \& Sanusi, M. Y. (2016). Muslims' views on the permissibility of organ donation: The case of Malaysia. IeJSME, 10(1), 41-46.

Vlaisavljevic, Z., Jankovic, S., \& Soldatovic, I. (2017). Survey of knowledge and attitudes of head nurses regarding organ transplantation. Acta Medica Medianae, 56(4), 38-44. https://doi.org/10.5633/amm.2017.0406

Williams, A. M., \& Muir, K. W. (2018).Awareness and attitudes toward corneal donation: challenges and opportunities. i: 1049-1059. https://doi.org/10.2147/OPTH.S142702

Yadav, N., Jakhar, J., Giri, S.K., Jain, P., Dahiya, S., \& Dhattarwal, S. K. (2018). Overview on Transplantation of Human Organs and Tissues Act. $J$ Punjab Acad Forensic Med Toxicol, 18(2), 100-106. https://doi.org/10.5958/0974-083X.2018.00043.2

Zambrano, A. (2017). Opt-in or opt-out to increase organ donation in South Africa? Appraising proposed strategies using an empirical ethics analysis. Social Theory and Practice, 43(1), 180-200. https://doi.org/10.5840/soctheorpract20174318

Zargham, A., Dorestan, N., Bahadoram, M., \& Bahadoram, S. (2018). Religious beliefs; Barrier or mainspring to organ donation. Journal of Nephropathology, 7(1), 17-18. https://doi.org/10.15171/jnp.2018.06

Zuniga-Fajuri, A. (2015). Increasing organ donation by presumed consent and allocation priority: Chile. Journal of Policy and Practice, 93, 199-202. https://doi.org/10.2471/BLT.14.139535

\section{Copyrights}

Copyright for this article is retained by the author(s), with first publication rights granted to the journal.

This is an open-access article distributed under the terms and conditions of the Creative Commons Attribution license (http://creativecommons.org/licenses/by/4.0/). 